Review Article

\title{
Oral Chinese Herbal Medicine for Treatment of Dilated Cardiomyopathy: A Systematic Review and Meta-Analysis
}

\author{
Yu-Shuo Zhu, ${ }^{1,2}$ Yun-Lun Li, ${ }^{1,2}$ Jian-Qing Ju, ${ }^{1,2}$ Feng Du, ${ }^{2}$ Yan-Ping Zang, ${ }^{2}$ \\ Xiao-Bing Wang, ${ }^{2}$ and Jie Sheng ${ }^{2}$ \\ ${ }^{1}$ Traditional Chinese Medicine Clinical Research Base for Hypertension, Affiliated Hospital of Shandong University of \\ Traditional Chinese Medicine, No. 42, Wenhua Xi Road, Jinan, Shandong 250011, China \\ ${ }^{2}$ Shandong University of Traditional Chinese Medicine, Jinan, Shandong 250355, China \\ Correspondence should be addressed to Yun-Lun Li; yunlun.lee@hotmail.com
}

Received 21 February 2016; Revised 29 June 2016; Accepted 6 July 2016

Academic Editor: Giuseppe Caminiti

Copyright (c) 2016 Yu-Shuo Zhu et al. This is an open access article distributed under the Creative Commons Attribution License, which permits unrestricted use, distribution, and reproduction in any medium, provided the original work is properly cited.

\begin{abstract}
Dilated cardiomyopathy (DCM) is one of the main causes of heart failure and could increase death, hospitalization, and rehospitalization rate. The effect of conventional medicine treatment (CMT) is limited; meanwhile, the combination of CMT and Oral Chinese Herbal Medicine (OCHM) represents exciting adjunctive therapies. In this study, we ascertained the therapeutic effect of OCHM in combination with CMT for dilated cardiomyopathy by using meta-analysis methods for controlled clinical trials. We searched studies from five databases and extracted data from these studies. We also assessed the methodological quality of the included studies. We evaluated the following outcome measures to estimate the prognosis in patients with DCM: left ventricular ejection fraction (LVEF), left ventricular end-diastolic dimension (LVEDD), stroke volume (SV), brain natriuretic peptide (BNP), 6-minute walk test (6MWT), and overall efficacy. The result showed that OCHM combined with CMT for the improvement of therapeutic effect in DCM patients. However, the evidence remains weak due to the small sample size, high clinical heterogeneity, and poor methodological quality of the included trials. Further, large sample size and well-designed trials are needed.
\end{abstract}

\section{Introduction}

Dilated cardiomyopathy (DCM), which can finally cause death by malignant ventricular arrhythmias, pump failure, or massive pulmonary embolism, is characterized by ventricular chamber enlargement and systolic dysfunction with normal LV wall thickness; usually diagnosis is made with 2-dimensional echocardiography [1]. DCM could not only obviously decrease every patients' quality of life, but also lead to higher death, hospitalization, and rehospitalization rate. The prevalence of DCM in the general population can only be estimated and clearly varies with age and geography [2]. In 1985 the National Centre for Health Statistics reported 10,345 deaths in the United States which could have been attributed to cardiomyopathy; about $87 \%$ of these were assigned to dilated cardiomyopathy [3]. In China the prevalence rate of DCM was 29.1 per 100,000 persons, the male being almost 2fold more involved than female, and farmers accounted for
$77.7 \%$ [4]. The case fatality rate of DCM was $15 \%$ $50 \%$ in 5 years [5] and brings serious burden to the society and the patients' family.

With the development of medicine, survival of adults with idiopathic DCM has improved in recent decades, with more than half surviving for 10 years $[6,7]$. Conventional medicine treatment (CMT) like conventional western medicine therapy is the standardized treatment for DCM. For DCM patients' overall survival is unsatisfactory; additional therapies are necessary for this stubborn and deadly disease. Complementary and alternative medicines can perhaps benefit DCM patients as an adjunctive therapy. In China, traditional Chinese medicine (TCM) combined with conventional western medicine is diffusely used to treat DCM. From some systematic reviews and clinical researches we can discover that "Huangqi injection" [8], "Qiliqiangxin Capsule" [9], and "Shenfu injection" [10] are all effective Chinese drugs pharmaceutics for treating DCM. However, a comprehensive 
review of the current evidence for the effects of Oral Chinese Herbal Medicine (OCHM) on curative effect in patients with DCM is not available.

This study aims to systematically evaluate the results of RCTs investigating OCHM combined with CMT in patients with DCM using EF, LVEDD, SV, BNP, 6-minute walk test $(6 \mathrm{MWT})$, and overall efficacy as outcome measures.

\section{Materials and Methods}

2.1. Searching Strategy. Randomized controlled trials (RCTs) assessing the administration of Oral Chinese Herbal Medicine (OCHM) in the treatment for DCM were located by searching the databases CNKI, WANFANG, VIP, PubMed, and the Cochrane Controlled Trials Register and assisted by manual retrieval. There is no restriction for publication language. The databases in Chinese were searched to obtain as much as possible relevant trials, because in China OCHM is generally used, and relevant theses were intensively published in Chinese journals. The last search was run on October 2015; case reports and small case series were excluded.

PubMed searching strategy includes the following:

\#1 chinese medicine
\#2 chinese drug
\#3 herb
\#4 chinese herb
\#5 herbal medicine
\#6 chinese herbal medicine
\#7 traditional chinese medicine
\#8 TCM
\#9 Chinese herbology
\#10 OR \#1-\#9
\#11 dilated cardiomyopathy
\#12 DCM
\#13 OR \#11-\#12
\#14 \#10 AND \#13

The search strategy was applied to PubMed and was adapted to other forms in other databases. These terms were translated into Chinese as key words when searching Chinese databases.

2.2. Inclusion Criteria. Search results were screened for trials by two reviewers (Yu-Shuo Zhu and Jian-Qing Ju). Two reviewers worked independently when using the following items as essential inclusion criteria:

(1) type of studies: randomized controlled trials (RCTs) with or without blinding;

(2) the inclusion of cases in line with national or international standards for the diagnosis of DCM and the average age of 18 years or older;
(3) trials containing patients with DCM being eligible, irrespective of the etiology, and DCM being diagnosed by the following criteria: DCM to be diagnosed according to the following accepted criteria of DCM: DCM diagnostic criteria established by WHO/ISFC [34], the concept and diagnosis criteria of DCM from textbook [35-38], and the summary of the symposium on myocarditis and cardiomyopathy in China [32, 33];

(4) the New York Heart Association (NYHA) functional class at II to IV;

(5) the treatment groups receiving Chinese medicine formulae together with conventional medicine treatment (CMT);

(6) the control groups receiving CMT only;

(7) CMT including interventions such as oxygen uptake, rest-cure, and low-salt diet, with medicines including angiotensin-converting enzyme (ACE) inhibitors, angiotensin-receptor blockers (ARBs), beta-receptor blockers, diuretics, aldosterone receptor blockers, digitalis preparation, drugs belonging to ester nitrate, and others recommended in the Chinese suggestions for diagnosis and treatment of cardiomyopathy;

(8) outcome measurements including at least 2 of these parameters: ejection fraction (EF), left ventricular end-diastolic dimension (LVEDD), stroke volume (SV), BNP, 6-minute walk test, and overall efficacy as outcome measures;

(9) treatment course: at least 2-week duration.

2.3. Exclusion Criteria. Exclusion criteria included the following items:

(1) quasi-randomized trials whose methods of allocation use date of birth, date of admission, or alternation;

(2) trials that included patients with acute heart failure;

(3) patients whose New York Heart Association (NYHA) functional class at II to IV was caused by no myocardiac pathogeny (like hyperthyreosis, spanemia, chronic left-sided heart failure, etc.);

(4) the treatment groups not receiving CMT or oral medicine;

(5) the treatment groups receiving Chinese patent medicine;

(6) the treatment groups receiving other traditional Chinese medicine (TCM) therapies such as acupuncture and moxibustion, massage, and ear pressure beans with or without OCHM.

2.4. Data Analysis. Two authors (Yu-Shuo Zhu and JianQing Ju) conducted the data extraction independently. The extracted data included authors, title of study, year of publication, sample size, age and sex of the participants, diagnosis standard, risk factors for $\mathrm{CHF}$, disease duration, New York 


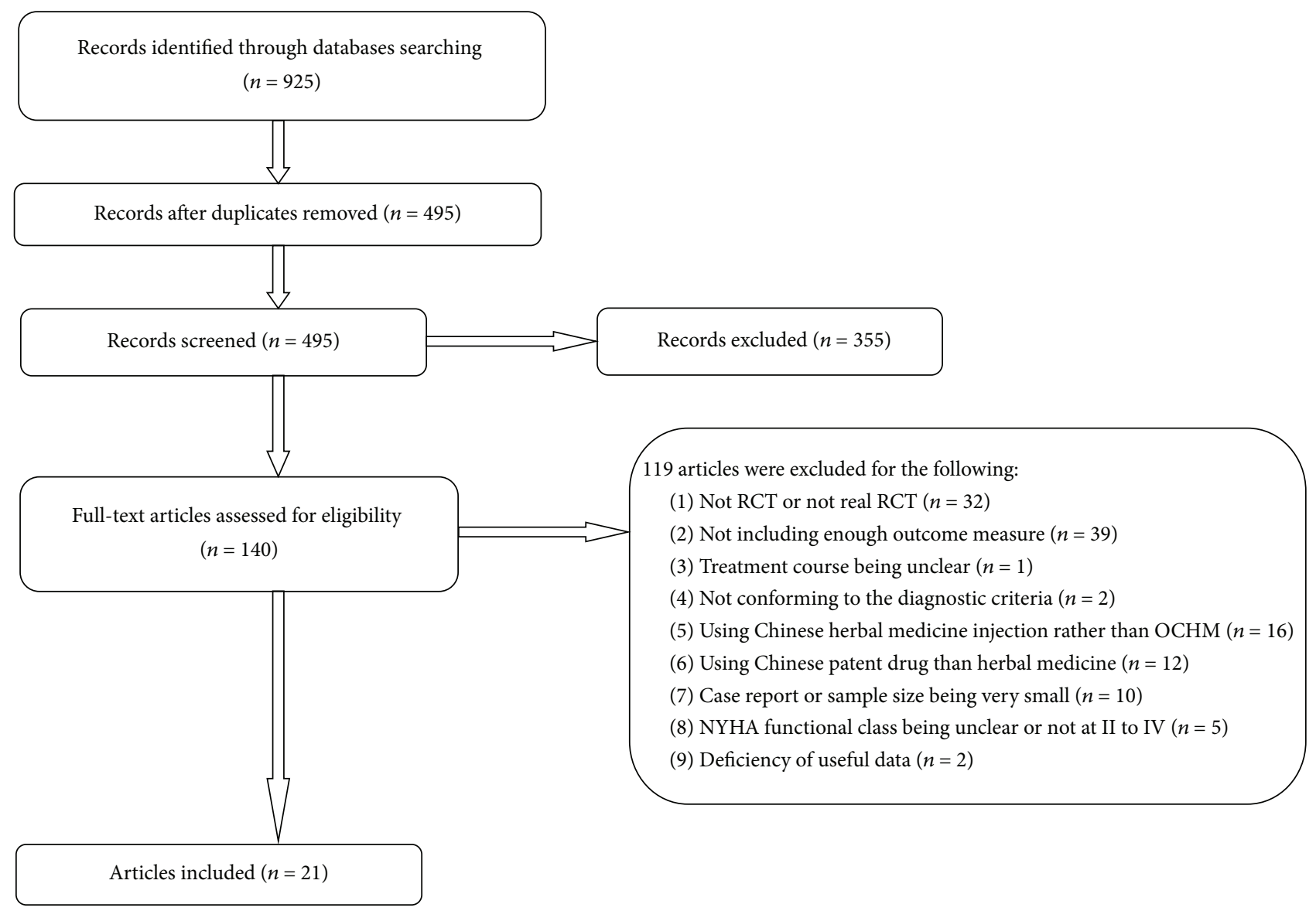

FIgURE 1: Flow chart of literature search.

Heart Association (NYHA) classification, name and component of Chinese herbs, details of the control interventions, course, follow-up, adverse effects of each study, and the details of methodological information. Disagreements were resolved by discussion, and consensus was reached through a third party (Yun-Lun Li). The methodological quality of trials was assessed independently using criteria from the Cochrane Handbook for Systematic Review of Interventions, version 5.1.0 [39]. The items included random sequence generation, allocation concealment, blinding, incomplete outcome data, selective outcome reporting, and other bias (defined as baseline data comparability). The risk of bias was categorized as low, unclear, or high.

When studies are gathered from the published literature, the random-effects model is generally a more plausible match [40]. Considering this is a more conservative method than a fixed-effect model and study heterogeneity can vary beyond chance, thus it provided a more conservative result. We used a random-effects model to estimate the overall effect when $P<0.1$. And when $P>0.1$, we choose the fixed-effect model. Statistical heterogeneity among trials was assessed by Cochrane's $Q$ test and $I^{2}$. Meta-analysis was conducted using RevMan 5.2 (Cochrane Collaboration).

\section{Results}

3.1. Description of Studies. After primary searches from the databases, 925 articles were screened. After removal of the duplicates, 495 records remained. After reading the titles and abstracts, 355 articles of them were excluded and full texts of 140 articles were retrieved. By reading the full texts of the remaining 140 articles, 119 articles were excluded for not meeting our inclusion criteria. Among them, 32 were excluded for not being RCT or not being real RCT, 39 for not including at least two of the parameters EF, LVEDD, SV, BNP, 6-minute walk test, and overall efficacy as outcome measures, 1 for treatment course being unclear, 2 for not conforming to the diagnostic criteria, 16 for using Chinese herbal medicine injection rather than oral administration, 12 for the treatment group receiving Chinese patent drug rather than herbal medicine; 10 for being case report or the sample size being very small, 5 for the NYHA functional class being unclear or not at II to IV, and 2 excluded due to deficiency of useful data for meta-analysis. Finally, 21 studies, involving a total of 1,566 participants, meet our inclusion criteria. The screening process was summarized in the flow diagram (Figure 1). 


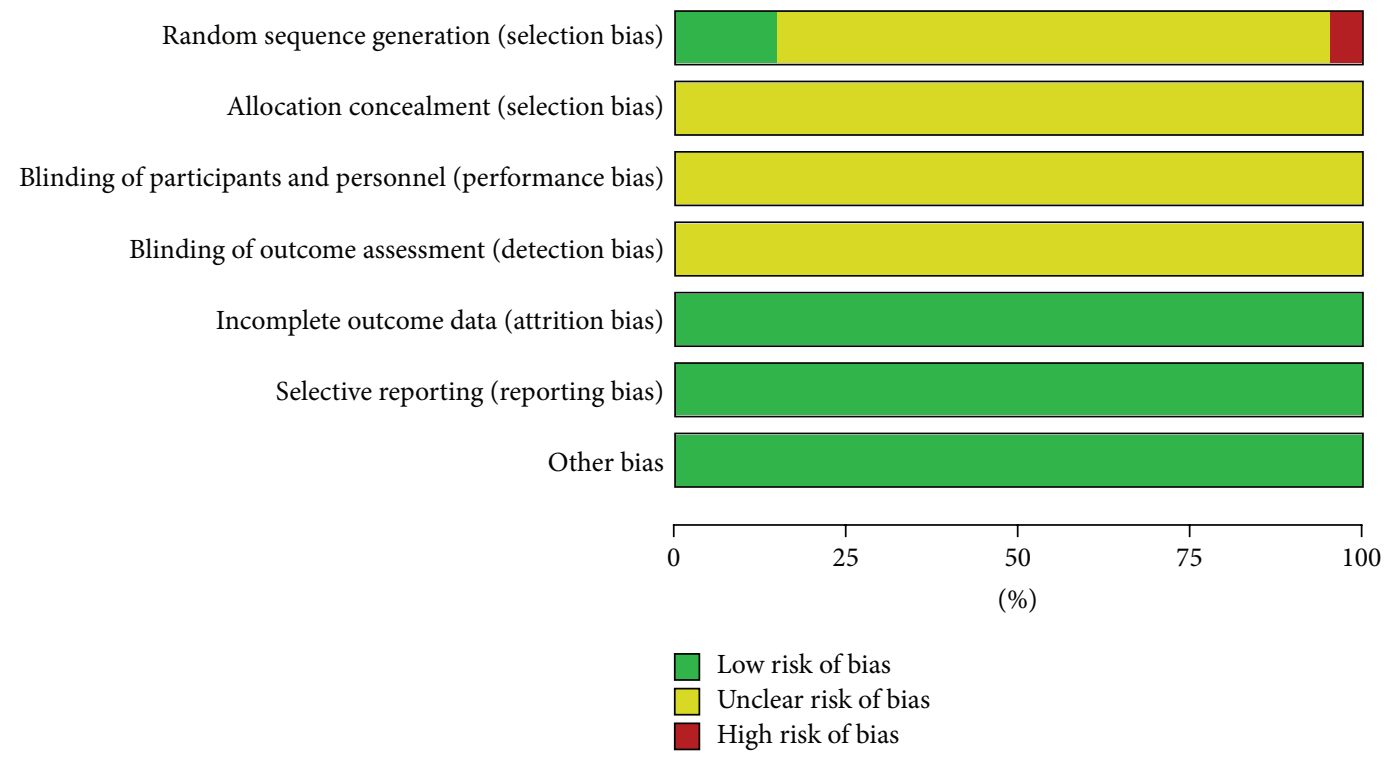

FIgURE 2: Risk of bias summary.

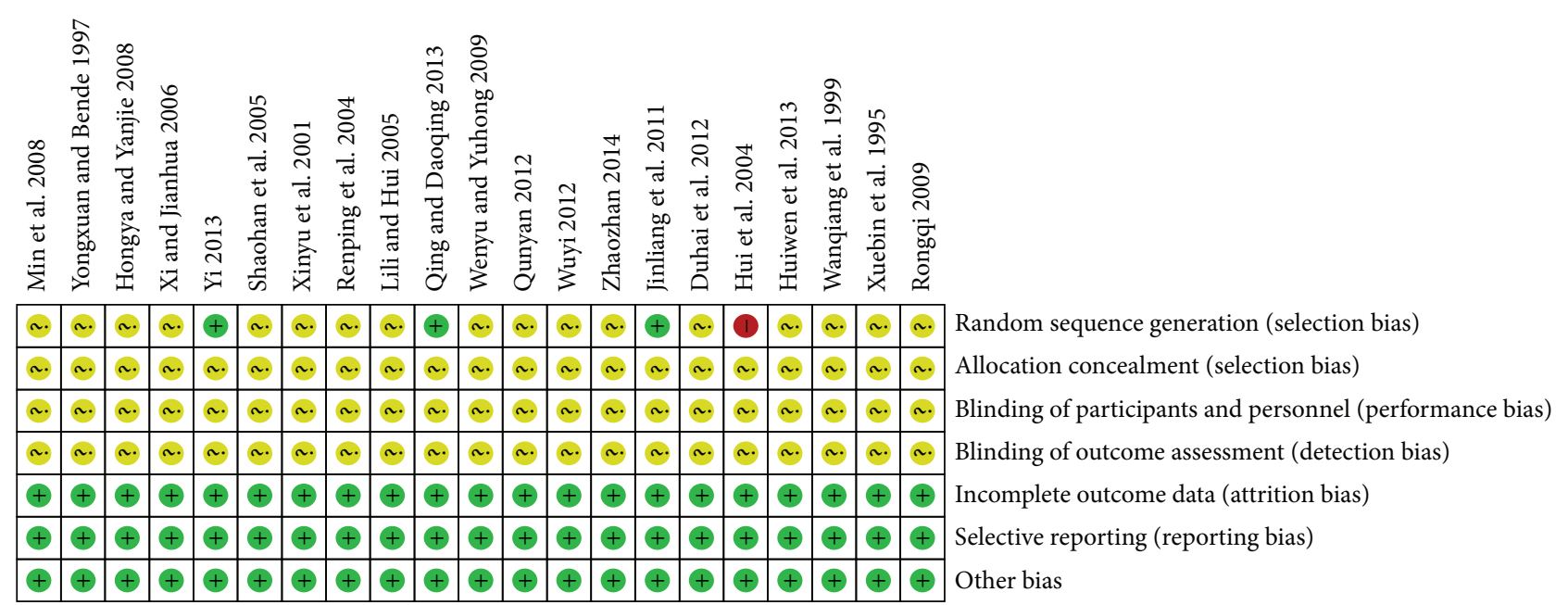

FIGURE 3: Risk of bias summary.

All the RCTs included in the meta-analysis were conducted in China and published in Chinese (the overview of the 21 studies included is indicated in Table 1). All of those studies were published in Chinese language. All studies were performed in China, and the studies involved a total of 1,566 patients with DCM. In addition, all studies exhibited comparable baseline patient characteristics, including age and gender. And there were no significant differences among them.

3.2. Risk of Bias Assessment. The majority of the included trials were assessed to be of poor methodological quality according to the predefined quality assessment criteria (Table 2).

The randomized allocation of participants was mentioned in all trials; however, only 3 trials $[17,18,41]$ stated the methods for sequence generation by random number table and one trial [23] by the order of treatment. Insufficient information was provided to judge whether or not it was conducted properly. No trials reported adequate allocation concealment. Neither double-blinding nor single-blinding was applied in these trials. None of the trials had a pretrial estimation of sample size. Five trials [21, 23, 26, 30, 31] mention follow-up. No trials reported dropout or withdrawal; meanwhile, none of them reported whether they had used intention-to-treat (ITT) analysis. All trials provided baseline data for the comparability among groups. The results of the assessment of risk of bias were presented in "risk of bias summary" figures produced by RevMan 5.2 (Figures 2 and 3).

\subsection{Clinical Effect}

3.3.1. Decrease of BNP. Figure 4 presents the findings of the 2 trials included for meta-analysis. For the 2 trials, OCHM plus CMT was found to be a significant method of decreasing 


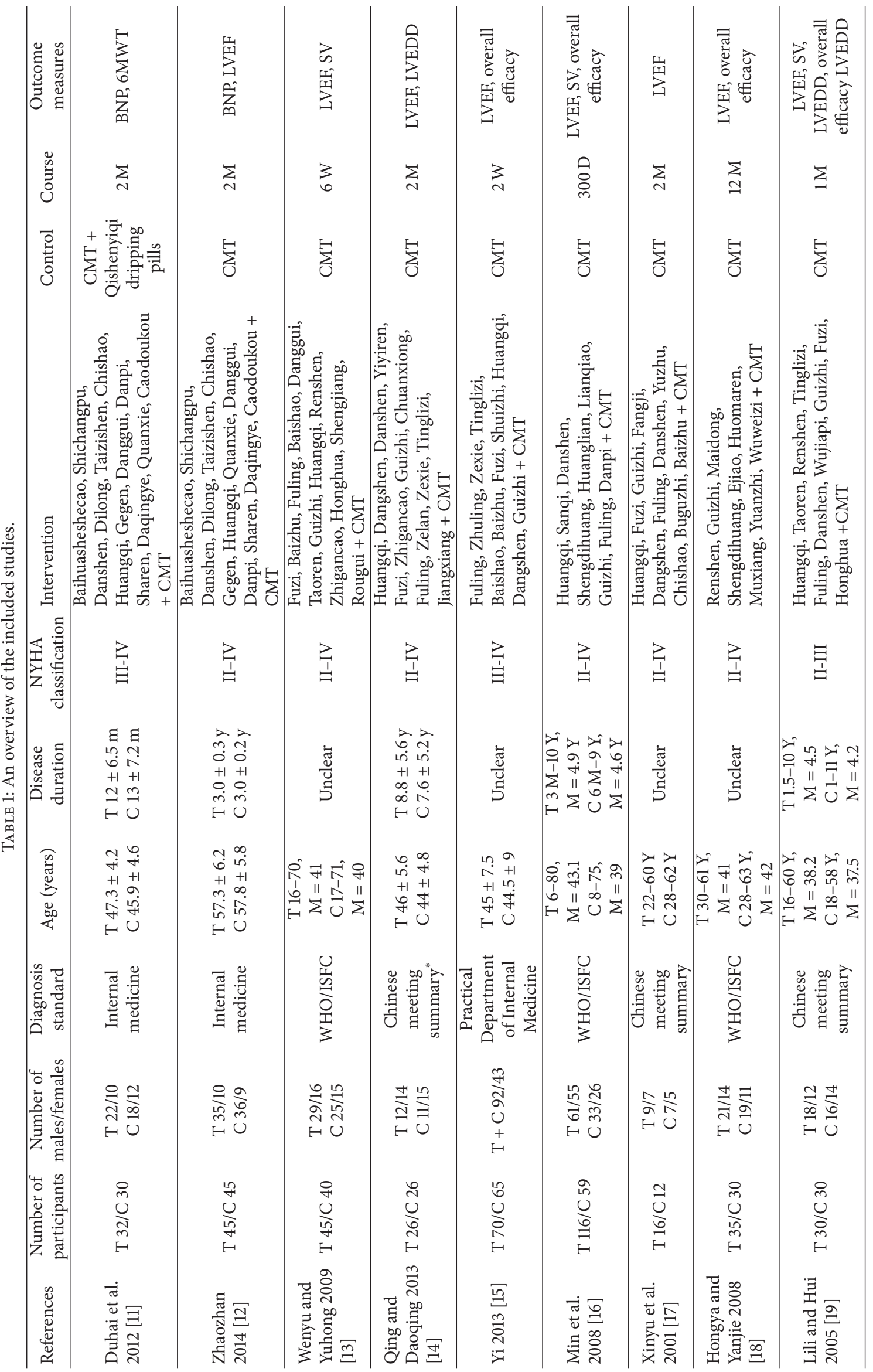




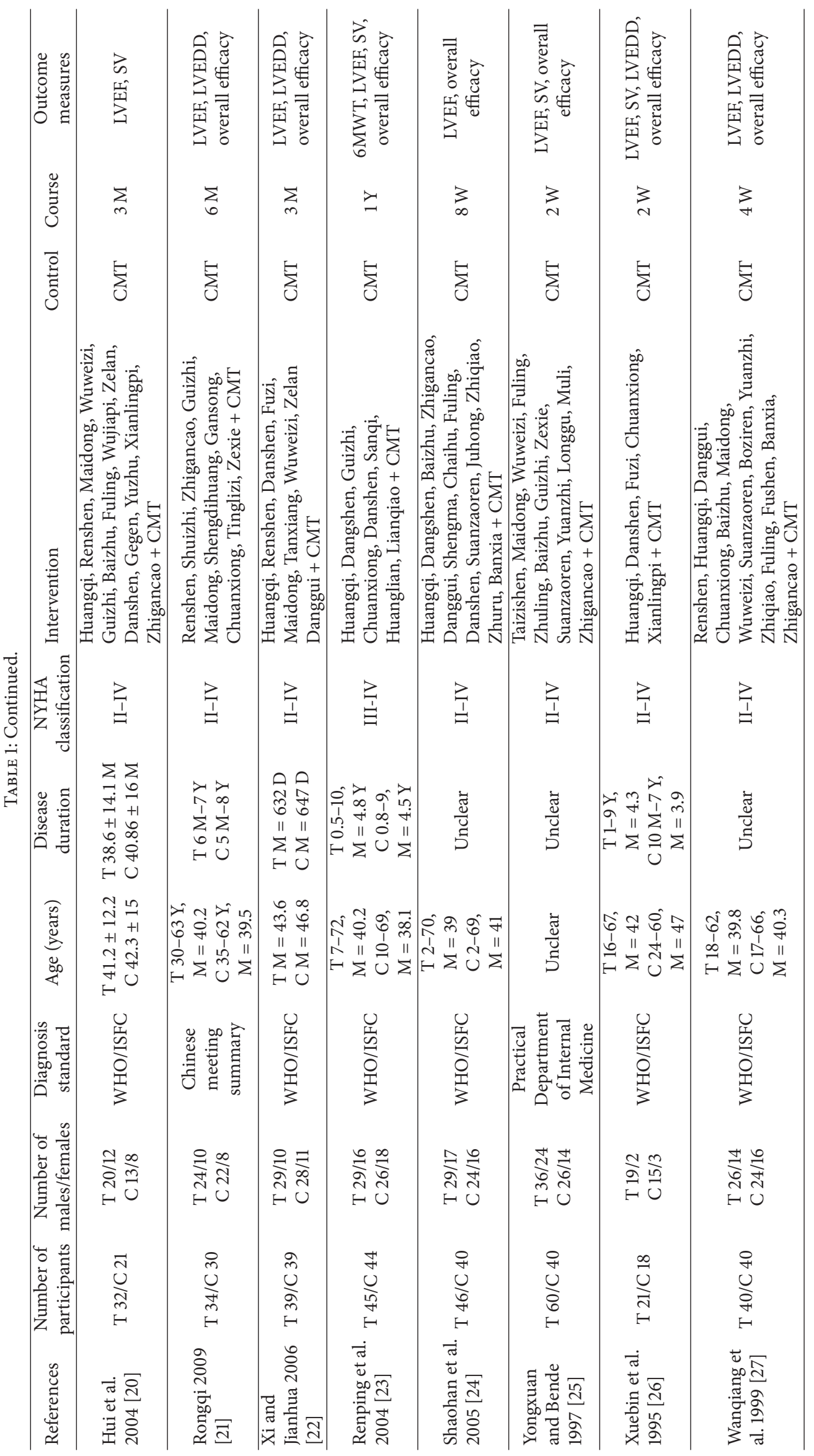




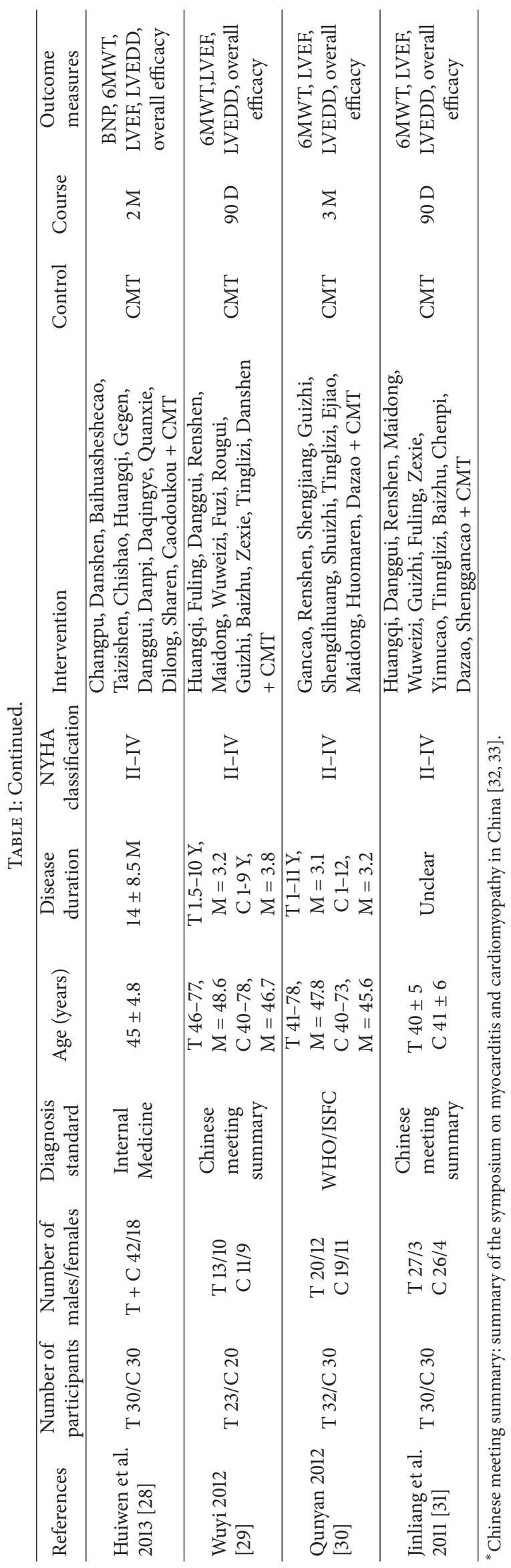


TABLE 2: The methodological quality of included trials.

\begin{tabular}{|c|c|c|c|c|c|c|c|}
\hline References & $\begin{array}{c}\text { Random } \\
\text { sequence } \\
\text { generation }\end{array}$ & $\begin{array}{c}\text { Allocation } \\
\text { concealment }\end{array}$ & Blinding & $\begin{array}{l}\text { Incomplete } \\
\text { outcome data }\end{array}$ & $\begin{array}{l}\text { Selective } \\
\text { outcome } \\
\text { reporting }\end{array}$ & $\begin{array}{l}\text { Baseline data } \\
\text { comparability }\end{array}$ & $\begin{array}{l}\text { Follow- } \\
\text { up }\end{array}$ \\
\hline Duhai et al. 2012 [11] & Unclear & Unclear & Unclear & No & No & Yes & No \\
\hline Zhaozhan 2014 [12] & Unclear & Unclear & Unclear & No & No & Yes & No \\
\hline Wenyu and Yuhong 2009 [13] & Unclear & Unclear & Unclear & No & No & Yes & No \\
\hline Qing and Daoqing 2013 [14] & $\begin{array}{c}\text { Random } \\
\text { number table }\end{array}$ & Unclear & Unclear & No & No & Yes & No \\
\hline Yi 2013 [15] & $\begin{array}{c}\text { Random } \\
\text { number table }\end{array}$ & Unclear & Unclear & No & No & Yes & No \\
\hline Min et al. 2008 [16] & Unclear & Unclear & Unclear & No & No & Yes & No \\
\hline Xinyu et al. 2001 [17] & Unclear & Unclear & Unclear & No & No & Yes & No \\
\hline Hongya and Yanjie 2008 [18] & Unclear & Unclear & Unclear & No & No & Yes & Yes \\
\hline Lili and Hui 2005 [19] & Unclear & Unclear & Unclear & No & No & Yes & No \\
\hline Hui et al. 2004 [20] & $\begin{array}{l}\text { Order of } \\
\text { treatment }\end{array}$ & Unclear & Unclear & No & No & Yes & Yes \\
\hline Rongqi 2009 [21] & Unclear & Unclear & Unclear & No & No & Yes & No \\
\hline $\mathrm{Xi}$ and Jianhua 2006 [22] & Unclear & Unclear & Unclear & No & No & Yes & No \\
\hline Renping et al. 2004 [23] & Unclear & Unclear & Unclear & No & No & Yes & Yes \\
\hline Shaohan et al. 2005 [24] & Unclear & Unclear & Unclear & No & No & Yes & No \\
\hline Yongxuan and Bende 1997 [25] & Unclear & Unclear & Unclear & No & No & Yes & No \\
\hline Xuebin et al. 1995 [26] & Unclear & Unclear & Unclear & No & No & Yes & No \\
\hline Wanqiang et al. 1999 [27] & Unclear & Unclear & Unclear & No & No & Yes & Yes \\
\hline Huiwen et al. 2013 [28] & Unclear & Unclear & Unclear & No & No & Yes & Yes \\
\hline Wuyi 2012 [29] & Unclear & Unclear & Unclear & No & No & Yes & No \\
\hline Qunyan 2012 [30] & Unclear & Unclear & Unclear & No & No & Yes & No \\
\hline Jinliang et al. 2011 [31] & $\begin{array}{c}\text { Random } \\
\text { number table }\end{array}$ & Unclear & Unclear & No & No & Yes & No \\
\hline
\end{tabular}

\begin{tabular}{|c|c|c|c|c|c|c|c|c|c|}
\hline \multirow{3}{*}{$\begin{array}{l}\text { Study or subgroup } \\
\text { Huiwen et al. } 2013\end{array}$} & \multicolumn{3}{|c|}{ Experimental } & \multicolumn{3}{|c|}{ Control } & \multirow{2}{*}{ Weight } & \multirow{2}{*}{$\begin{array}{c}\text { Mean difference } \\
\text { IV, random, 95\% CI }\end{array}$} & \multirow{2}{*}{$\begin{array}{c}\text { Mean difference } \\
\text { IV, random, 95\% CI }\end{array}$} \\
\hline & \multirow{2}{*}{$\frac{\text { Mean }}{523.4}$} & \multirow{2}{*}{$\frac{\mathrm{SD}}{60.4}$} & \multirow{2}{*}{$\frac{\text { Total }}{30}$} & \multirow{2}{*}{$\frac{\text { Mean }}{611.3}$} & \multirow{2}{*}{$\frac{S D}{72.1}$} & \multirow{2}{*}{$\frac{\text { Total }}{30}$} & & & \\
\hline & & & & & & & $50.3 \%$ & $-87.90[-121.56,-54.24]$ & -1 \\
\hline Duhai et al. 2012 & 365 & 49 & 32 & 566 & 93 & 30 & $49.7 \%$ & $-201.00[-238.36,-163.64]$ & \\
\hline Total (95\% CI) & & & 62 & & & 60 & $100.0 \%$ & $-144.15[-254.98,-33.31]$ & \\
\hline Heterogeneity: $\tau^{2}=$ & 5066.70 & $x^{2}$ & $9.43, \mathrm{~d}$ & $=1(P$ & $<0.0$ & $01) ; I^{2}$ & $=95 \%$ & & $\begin{array}{cccc}1 & 1 & 1 & 1 \\
-200-100 & 0 & 100 & 200\end{array}$ \\
\hline Test for overall effec & $Z=2$. & $5(P=$ & $0.01)$ & & & & & & Favours OCHM + CMT Favours CMT \\
\hline
\end{tabular}

FIGURE 4: Forest plot of decrease of patients' BNP.

plasma brain natriuretic peptide (BNP) when compared to the control group. Meta-analysis shows a significant improvement in BNP [MD $=-144.15,95 \%$ CI $[-254.98,-33.31]$, and $P=0.01]$, which means that OCHM plus CMT is significantly better than CMT in decreasing BNP of heart. Highly significant heterogeneity was found among these 2 studies $\left(\chi^{2}=19.43, I^{2}=95 \%\right.$, and $\left.P<0.0001\right)$, indicating their heterogeneity.
3.3.2. Improvement of $L V E D D, E F$, and $S V$. The randomeffects model was used for statistical analysis as the heterogeneity was expected. Among the 20 studies involving left ventricular ejection fraction (LVEF), OCHM plus CMT was found to be a significant method to improve left ventricular function when compared to CMT. Meta-analysis shows a significant improvement in EF [MD $=0.06,95 \%$ CI [0.04, 0.08], and $P<0.0001]$, which means that OCHM plus CMT 


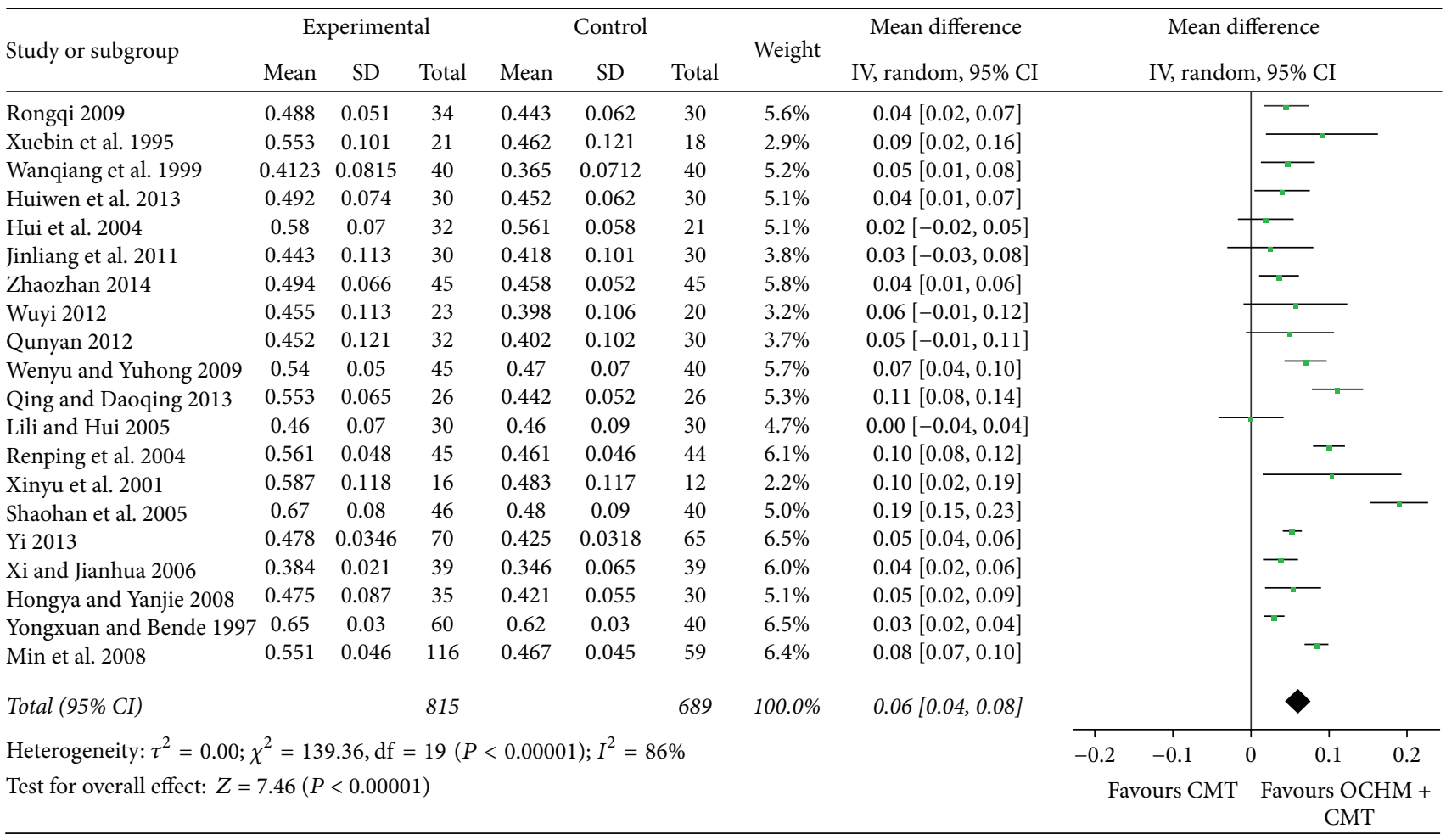

FIgURE 5: Forest plot of improvement of patients' LVEF.

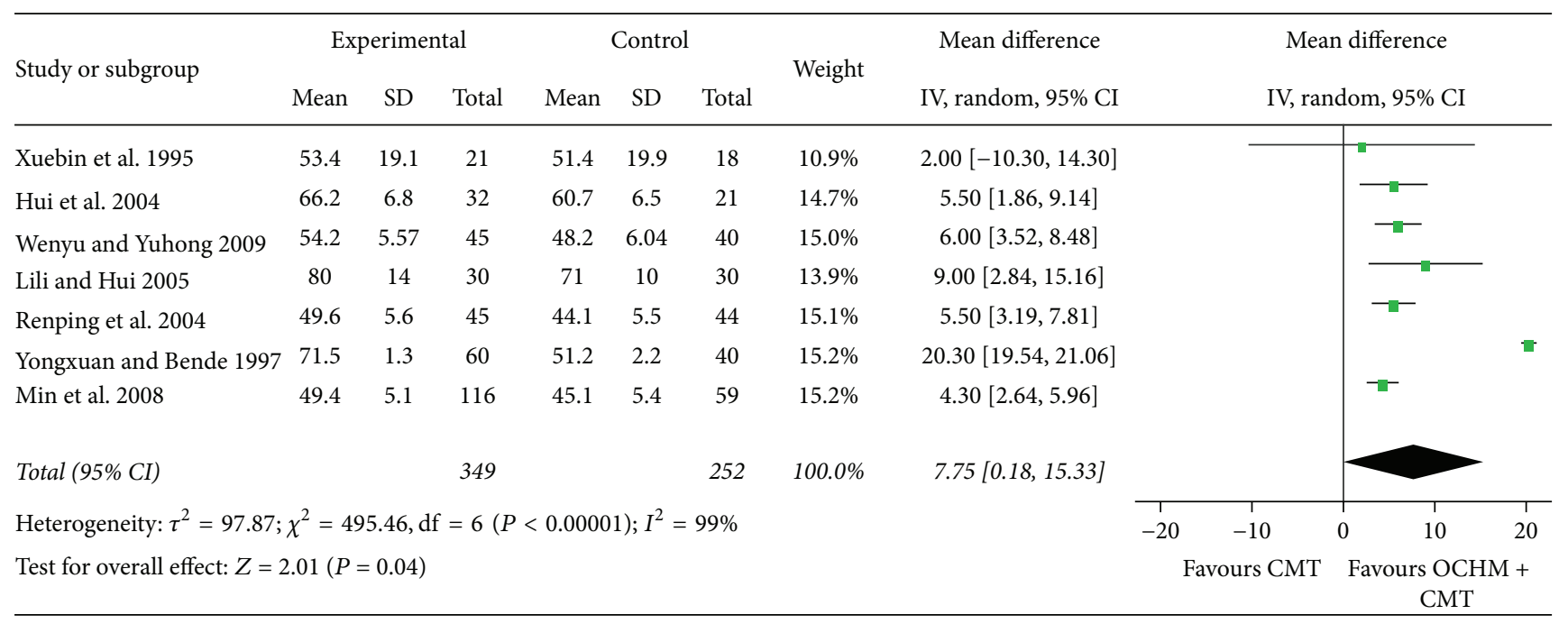

FIgURE 6: Forest plot of improvement of patients' SV.

is significantly better than CMT in improving ventricular ejection fraction. Highly significant heterogeneity was found among these 20 studies $\left(\chi^{2}=139.36, I^{2}=86 \%\right.$, and $P<$ 0.00001 ), indicating their heterogeneity (Figure 5).

For the 7 studies mentioning stroke volume (SV), metaanalysis shows a significant improvement in SV [MD $=7.75$, 95\% CI $[0.18,15.33]$, and $P=0.04]$, which means that OCHM plus CMT is significantly better than CMT in increasing SV. Highly significant heterogeneity was found among these 7 studies $\left(\chi^{2}=495.46, I^{2}=99 \%\right.$, and $\left.P<0.00001\right)$, indicating their heterogeneity (Figure 6).

Meta-analysis shows a significant improvement in LVEDD $[\mathrm{MD}=-3.72,95 \%$ CI $[-4.84,-2.60]$, and $P<0.00001]$, which means that OCHM plus CMT is significantly better than CMT in narrowing left ventricular end-diastolic dimension. Low heterogeneity was found among these 11 studies $\left(\chi^{2}=16.49, I^{2}=39 \%\right.$, and $\left.P=0.09\right)$ (Figure 7). 


\begin{tabular}{|c|c|c|c|c|c|c|c|c|c|c|c|c|}
\hline \multirow{3}{*}{$\begin{array}{l}\text { Study or subgroup } \\
\text { Rongqi } 2009\end{array}$} & \multicolumn{3}{|c|}{ Experimental } & \multicolumn{3}{|c|}{ Control } & \multirow{2}{*}{ Weight } & \multirow{2}{*}{$\begin{array}{c}\text { Mean difference } \\
\text { IV, random, 95\% CI }\end{array}$} & \multirow{2}{*}{\multicolumn{4}{|c|}{$\begin{array}{c}\text { Mean difference } \\
\text { IV, random, 95\% CI }\end{array}$}} \\
\hline & \multirow{2}{*}{$\begin{array}{c}\text { Mean } \\
52.3\end{array}$} & \multirow{2}{*}{$\begin{array}{l}S D \\
6.3\end{array}$} & \multirow{2}{*}{$\begin{array}{c}\text { Total } \\
34\end{array}$} & \multirow{2}{*}{$\begin{array}{l}\text { Mean } \\
57.08\end{array}$} & \multirow{2}{*}{$\begin{array}{l}\mathrm{SD} \\
5.9\end{array}$} & \multirow{2}{*}{$\begin{array}{c}\text { Total } \\
30\end{array}$} & & & & & & \\
\hline & & & & & & & $8.9 \%$ & $-4.78[-7.77,-1.79]$ & & - & & \\
\hline Xuebin et al. 1995 & 57.4 & 3.8 & 21 & 62.8 & 3.7 & 18 & $11.6 \%$ & $-5.40[-7.76,-3.04]$ & & — & & \\
\hline Wanqiang et al. 1999 & 57.4 & 6.3 & 40 & 59.8 & 6.9 & 40 & $9.2 \%$ & $-2.40[-5.30,0.50]$ & & & & \\
\hline Huiwen et al. 2013 & 49.57 & 4.24 & 30 & 54.4 & 3.17 & 30 & $14.2 \%$ & $-4.83[-6.72,-2.94]$ & & - & & \\
\hline Hui et al. 2004 & 51.8 & 8.2 & 32 & 54.5 & 8 & 21 & $5.0 \%$ & $-2.70[-7.15,1.75]$ & & & & \\
\hline Jinliang et al. 2011 & 59.9 & 7.1 & 30 & 61.3 & 7.4 & 30 & $6.7 \%$ & $-1.40[-5.07,2.27]$ & & & & \\
\hline Wuyi 2012 & 58.9 & 5.1 & 23 & 61.7 & 6.3 & 20 & $7.3 \%$ & $-2.80[-6.26,0.66]$ & & & & \\
\hline Qunyan 2012 & 59.4 & 5.2 & 32 & 61.6 & 6.2 & 30 & $9.4 \%$ & $-2.20[-5.06,0.66]$ & & & & \\
\hline Qing and Daoqing 2013 & 49.8 & 5.5 & 26 & 56.7 & 9.1 & 26 & $5.7 \%$ & $-6.90[-10.99,-2.81]$ & & - & & \\
\hline Lili and Hui 2005 & 53.2 & 5.4 & 30 & 54.3 & 4.2 & 30 & $11.2 \%$ & $-1.10[-3.55,1.35]$ & & $\longrightarrow$ & & \\
\hline $\mathrm{Xi}$ and Jianhua 2006 & 56.19 & 6.3 & 39 & 61.82 & 5.1 & 39 & $10.7 \%$ & $-5.63[-8.17,-3.09]$ & & - & & \\
\hline Total (95\% CI) & & & 337 & & & 314 & $100.0 \%$ & $-3.72[-4.84,-2.60]$ & & & & \\
\hline Heterogeneity: $\tau^{2}=1.36$ & $; x^{2}=1$ & $49, \mathrm{df}$ & $=10(P$ & $=0.09)$; & $2=390$ & & & & -10 & 0 & 5 & 10 \\
\hline Test for overall effect: $Z=$ & $=6.52(1$ & $<0.00$ & & & & & & & $\begin{array}{r}\text { Favours } \\
\mathrm{CD}\end{array}$ & $\begin{array}{l}\mathrm{OCHM}+ \\
\text { MT }\end{array}$ & Favours & CMT \\
\hline
\end{tabular}

FIGURE 7: Forest plot of improvement of patients' LVEDD.

\begin{tabular}{|c|c|c|c|c|c|c|c|c|c|c|c|}
\hline \multirow{3}{*}{$\begin{array}{l}\text { Study or subgroup } \\
\text { Huiwen et al. } 2013\end{array}$} & \multicolumn{3}{|c|}{ Experimental } & \multicolumn{3}{|c|}{ Control } & \multirow{2}{*}{ Weight } & \multirow{2}{*}{$\begin{array}{c}\text { Mean difference } \\
\text { IV, random, 95\% CI }\end{array}$} & \multirow{2}{*}{\multicolumn{3}{|c|}{$\begin{array}{c}\text { Mean difference } \\
\text { IV, random, 95\% CI }\end{array}$}} \\
\hline & \multirow{2}{*}{$\begin{array}{c}\text { Mean } \\
387.32\end{array}$} & \multirow{2}{*}{$\frac{\mathrm{SD}}{49.8}$} & \multirow{2}{*}{$\begin{array}{c}\text { Total } \\
30\end{array}$} & \multirow{2}{*}{$\begin{array}{l}\text { Mean } \\
352.38\end{array}$} & \multirow{2}{*}{$\frac{\mathrm{SD}}{51.47}$} & \multirow{2}{*}{$\begin{array}{c}\text { Total } \\
30\end{array}$} & & & & & \\
\hline & & & & & & & $14.2 \%$ & $34.94[9.31,60.57]$ & & - & \\
\hline Duhai et al. 2012 & 369.8 & 62.4 & 32 & 235.6 & 60.5 & 30 & $12.8 \%$ & $134.20[103.60,164.80]$ & & & - \\
\hline Jinliang et al. 2011 & 546.2 & 11.5 & 30 & 428.8 & 9.4 & 30 & $18.9 \%$ & $117.40[112.09,122.71]$ & & & $=$ \\
\hline Wuyi 2012 & 562.2 & 13.8 & 23 & 408.8 & 11.5 & 20 & $18.6 \%$ & $153.40[145.84,160.96]$ & & & - \\
\hline Qunyan 2012 & 558.2 & 11.8 & 32 & 418.8 & 10.2 & 30 & $18.9 \%$ & $139.40[133.92,144.88]$ & & & - \\
\hline Renping et al. 2004 & 380.4 & 45 & 45 & 245 & 38 & 44 & $16.6 \%$ & $135.40[118.11,152.69]$ & & & -- \\
\hline Total (95\% CI) & & & 192 & & & 184 & $100.0 \%$ & $121.69[102.80,140.58]$ & & & \\
\hline Heterogeneity: $\tau^{2}=$ & $=483.38$ & $=121$ & $\mathrm{ff}=5$ & $P<0.0$ & $001) ; I^{2}$ & $=96 \%$ & & & $-100-50$ & 50 & 100 \\
\hline Test for overall effec & $\mathrm{ct}: Z=12$ & $(P<$ & & & & & & & Favours CMT & $\begin{array}{r}\text { Favours } \\
\mathrm{C}\end{array}$ & $\begin{array}{l}\mathrm{OCHM}+ \\
\text { MT }\end{array}$ \\
\hline
\end{tabular}

FIGURE 8: Forest plot of improvement of patients' 6MWT.

3.3.3. 6MWT. 15 studies comparing OCHM plus CMT versus CMT found that OCHM plus CMT achieved a greater improvement than using CMT only $[\mathrm{MD}=121.69,95 \% \mathrm{CI}$ $[102.80,140.58]$, and $P<0.00001]$, which means that OCHM plus CMT is significantly better than CMT in increasing the exercise tolerance. Highly significant heterogeneity was found among these 6 studies $\left(\chi^{2}=121.97, I^{2}=96 \%\right.$, and $P<0.00001)$. The results of the meta-analysis are shown in Figure 8.

3.3.4. Overall Efficacy. In this meta-analysis we chose the fixed-effect model, and it shows a significant improvement in overall efficacy $[\mathrm{RR}=1.26,95 \%$ CI $[1.19,1.33]$, and $P<$ 0.00001 ], which means that OCHM plus CMT is significantly better than CMT in acquiring better curative effect (Figure 9).

\section{Discussion}

DCM is a kind of refractory cardiomyopathy and its cause is still not clear; the majority of Chinese and foreign scholars believe that the occurrence and development of DCM rely on the resulting myocardial autoimmune injury and the persistent viral infection [42]. Based on CMT, although the long-term survival rate of patients has been improved, because of the complexity of the pathological and physiological mechanism of DCM itself, the treatment method has not yet achieved satisfactory clinical results. As a complementary and alternative therapy, TCM has increasingly drawn a wider range of interest among DCM studies because it can increase the efficacy when combined with CMT.

Echocardiograph is an effective adjunct for cardiac function or structure assessment in cardiomyopathy diagnosis 


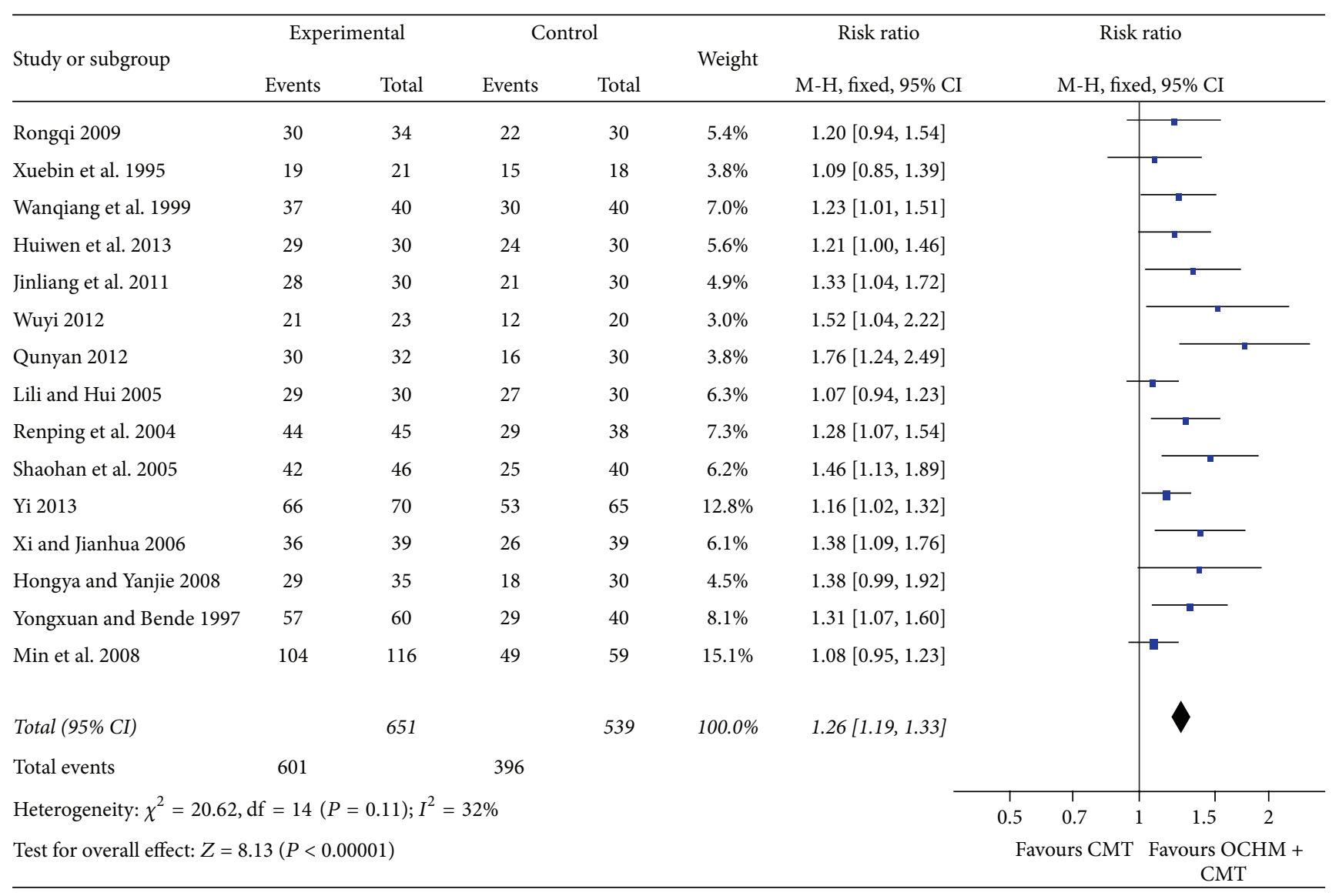

Figure 9: Forest plot of overall efficacy.

and evaluation. Many experiments show that the degree of left ventricular dysfunction is the most important prognostic factor of DCM patients. Parameters like left ventricular ejection fraction (LVEF), left ventricular end-diastolic dimension (LVEDD), and stroke volume (SV) reflect left ventricular function and size. Left ventricular ejection fraction (LVEF) provides useful diagnostic and prognostic information for patients with idiopathic dilated cardiomyopathy [5, 41]. Stroke volume (SV) and its derivative index are the result of left ventricular preload, afterloading, and myocardial contractility's synthetic action. This type of index is significantly affected by left ventricular preload and afterloading. 6MWT, a submaximal exercise test, simply measures the distance ambulated on a level hallway surface during $6 \mathrm{~min}$ [43]. The $6 \mathrm{MWT}$ is a simple clinical tool to assess cardiac functional capacity and to predict patient's status. The Seattle Heart Failure Study has shown that serum parameters can be as important as echocardiography in predicting outcomes and also add BNP to the model to perfect the prognostic power of the score [44].

4.1. Main Findings. 21 RCTs and 1,566 participants were included in this review. Our meta-analysis of the overall effect rate found that OCHM combined with CMT were more effective than CMT for the treatment of DCM. This study also shows that the use of oral herbal medicine for the treatment of DCM based on CMT can provide a satisfactory therapeutic effect to patients with different gender, different age, and different degree, by improving the cardiac function and regulating atrioventricular size, and improve the exercise tolerance of patients. From this we can infer that OCHM plays a similar role in enhancing myocardial contractility, diuretic, dilation of blood vessels, antimyocardial ischemia, inhibiting myocardial remodeling, and so on, which can be similar to CMT.

4.2. About OCHM. The efficacy of different drugs used in these experiments is mainly reflected in improving myocardial contractile function, improving myocardial metabolism, improving vascular endothelial function, antiplatelet aggregation, regulating the immune function, improving the body's resistance, protecting ischemic and hypoxia myocardium, clearing virus persistent infection, and so on.

Modern pharmacological studies confirmed that Danshen can increase plasma CGRP, reduce plasma endothelin levels, reduce the plasma and myocardial local Ang II, and promote myocardial repair [45]. Huangqi could promote cell metabolism, improve the ability of myocardial hypoxia tolerance [46], reduce rennin-angiotensin and brain natriuretic peptide level [47], reduce the preload and afterload, enhance myocardial contractility, and improve heart function from many aspects. Gegen has the function of expanding peripheral blood vessels and contains puerarin which can further 
reduce the level of serum BNP in patients with heart failure [48]. The effective components of Chuanxiong (like ligustrazine and ferulic acid) have the function of vasodilation, improving microcirculation, and antimyocardial ischemia. Renshen, Tinglizi can enhance myocardial contractility and increased cardiac output function $[49,50]$. In addition, astragaloside can promote macrophages' synthesis of primary lysosomes and regulate secretion of IL-1 in macrophages $[42,51]$. Ginsenoside can reduce the open probability of B type, $\mathrm{L}$ type, and $\mathrm{T}$ type calcium ion in rats' myocardial cells, shorten the opening time, promote the gene expression of lymphocyte IL-1 and IL-6 [42, 51]. Huangqi has antiviral and immune regulation effects and improves heart function [52].

4.3. Limitations of This Review. The included studies had limitations in methodological qualities. Only 3 of the trials reported on how the participants are randomly assigned to the intervention groups. The other trials simply mention "randomization," with none of the trials mentioning the use of allocation concealment and blinding. Five of the trials mention follow-up.

Overview of the literature collected by this study: although results showed that OCHM in patients with DCM have significantly increased left ventricular ejection function, delay ventricular enlargement, and improve exercise tolerance, the literature quality is still low.

This study suggests that oral herbal medicine can effectively improve the cardiac function of patients with DCM, but the results have very significant heterogeneity; the reason may be that the quality of current domestic clinical research is not high. What is more, the clinical samples are small, the observation time is short, and the relevant evidence-based data needs further observation; all of these items restrict the promotion of the level.

This affects the evaluation objective effect in a certain extent. We expect to carry out higher standard randomized clinical trial and mechanism revealing of oral herbal medicine, in order to overcome the DCM, a severe case in the modern medicine.

\section{Conclusions}

In recent years, system evaluation and meta-analysis have been widely used in clinical medicine, public health, molecular genetics, drug evaluation, medical insurance, medical education, and many other biomedical fields. Meta-analysis can be used to increase the sample size and improve the efficacy of the test, especially when multiple results are inconsistent or not statistically significant. Meta-analysis can be used to get more close to the real situation of the comprehensive results [53].

The combination of oral herbal medicine and CMT can be used as an effective therapy of DCM; the specific mechanism needs further study.

From the traditional Chinese medicine diagnosis and treatment based on syndrome differentiation to confirm its own theoretical advantages, we can clearly conclude that the effective law and scientific induction of the high repeatability of the treatment experience still need to be further explored.

\section{Competing Interests}

The authors declare that there are no competing interests regarding the publication of this paper.

\section{References}

[1] B. J. Maron, J. A. Towbin, G. Thiene et al., "Contemporary definitions and classification of the cardiomyopathies: an American Heart Association Scientific Statement from the Council on Clinical Cardiology, Heart Failure and Transplantation Committee; Quality of Care and Outcomes Research and Functional Genomics and Translational Biology Interdisciplinary Working Groups; and Council on Epidemiology and Prevention," Circulation, vol. 113, no. 14, pp. 1807-1816, 2006.

[2] S. Pankuweit, C. Lüers, A. Richter, V. Ruppert, G. Gelbrich, and B. Maisch, "Influence of different aetiologies on clinical course and outcome in patients with dilated cardiomyopathy," European Journal of Clinical Investigation, vol. 45, no. 9, pp. $906-$ 917, 2015.

[3] R. F. Gillum, "Idiopathic cardiomyopathy in the United States, 1970-1982," American Heart Journal, vol. 111, no. 4, pp. 752-755, 1986.

[4] H. Guangyong, G. Hang, M. Xiangang et al., "Epidemiology and etiology of dilated cardiomyopathy," Journal of Prevention and Control of Chronic Diseases in China, vol. 1, pp. 42-44, 2009.

[5] M. Komajda, J. P. Jais, F. Reeves et al., "Factors predicting mortality in idiopathic dilated cardiomyopathy," European Heart Journal, vol. 11, no. 9, pp. 824-831, 1990.

[6] Y. Matsumura, E. Hoshikawa-Nagai, T. Kubo et al., "Left ventricular reverse remodeling in long-term (>12 Years) survivors with idiopathic dilated cardiomyopathy," American Journal of Cardiology, vol. 111, no. 1, pp. 106-110, 2013.

[7] M. M. Redfield, B. J. Gersh, K. R. Bailey, D. J. Ballard, and R. J. Rodeheffer, "Natural history of idiopathic dilated cardiomyopathy: effect of referral bias and secular trend," Journal of the American College of Cardiology, vol. 22, no. 7, pp. 1921-1926, 1993.

[8] B. Zhouyan, T. Qizhu, L. Fangfang, and W. Wen, "A systematic review of the effect of Astragalus Injection in the treatment of dilated cardiomyopathy," Journal of Medical Research, vol. 11, pp. 70-72, 2011.

[9] Z. Xueli, C. Kuaile, Y. Jun, and T. Lili, "40 Patients with dilated cardiomyopathy treated Qiliqiangxin capsule," Shaanxi Traditional Chinese Medicine, vol. 5, pp. 549-551, 2010.

[10] J. Qiulei, H. Yuanhui, S. Qingqiao et al., "Effectiveness and safety of Shen Fu Injection in the treatment of dilated cardiomyopathy," Chinese Journal of Evidence Based Medicine, vol. 5, pp. 609613, 2015.

[11] G. Duhai, D. Huiwen, H. Zhaozhan et al., "Clinical observation on treatment of 32 cases with dilated cardiomyopathy by Changpu Qidan Decoction," Hebei Traditional Chinese Medicine, vol. 9, pp. 1326-1327, 2012.

[12] H. Zhaozhan, "Clinical study on the treatment of dilated cardiomyopathy by Changpu Qidan Decoction," Hebei Traditional Chinese Medicine, vol. 7, pp. 983-985, 2014.

[13] L. Wenyu and L. Yuhong, "Curative effect observation on 45 cases of dilated cardiomyopathy with heart failure treated with Jian Xin Decoction," Yunnan Journal of Traditional Chinese Medicine, vol. 4, pp. 24-25, 2009.

[14] L. Qing and H. Daoqing, "To observe the curative effect of Qifu Yangxin Decoction in the treatment of dilated cardiomyopathy," 
Shanxi Traditional Chinese Medicine, vol. 10, pp. 1277-1278, 2013.

[15] Y. Yi, "Lingxie Qiangxin Decoction in treating 70 patients with yang deficiency and water deluge generic dilated cardiomyopathy," Journal of Cardiovascular and Cerebrovascular Diseases, vol. 11, pp. 1311-1312, 2013.

[16] Z. Min, W. Lei, and W. Renping, "Clinical observation on treatment of 116 cases with dilated cardiomyopathy by Xinji Huoli Decoction," Hebei traditional Chinese Medicine, vol. 9, pp. 954-955, 2008.

[17] W. Xinyu, L. Shu, G. Shaoyu et al., "Clinical observation on treatment of dilated cardiomyopathy by Xinlishen decoction," New Traditional Chinese Medicine, no. 3, pp. 20-22, 2001.

[18] Y. Hongya and D. Yanjie, "Clinical observation of 35 cases of Zhigancao Decoction in patients with dilated cardiomyopathy," Journal of Cardiovascular and Cerebrovascular Diseases, vol. 11, pp. 1269-1270, 2008.

[19] S. Lili and Z. Hui, "Clinical observation of traditional Chinese medicine combined with western medicine on 30 patients with dilated cardiomyopathy," Traditional Chinese Medicine Information, vol. 1, pp. 25-26, 2005.

[20] F. Hui, W. Xiaodong, X. Xiaopeng, and C. Jing, "Clinical observation of traditional Chinese Medicine Combined with Western Medicine on 32 Patients with Dilated Cardiomyopathy," Journal of Traditional Chinese Medicine, vol. 12, pp. 2328-2329, 2004.

[21] B. Rongqi, "Observation of traditional Chinese medicine combined with western medicine on 34 patients with dilated cardiomyopathy," Journal of Practical Traditional Chinese Medicine, vol. 10, pp. 678-679, 2009.

[22] Y. Xi and C. Jianhua, "Clinical observation of traditional Chinese medicine combined with western medicine on 39 patients with dilated cardiomyopathy," Gansu Traditional Chinese Medicine, vol. 5, pp. 15-16, 2006.

[23] W. Renping, D. Sushe, M. Fangfei et al., "Clinical observation of Traditional Chinese Medicine combined with western medicine on 45 patients with dilated cardiomyopathy," Chinese Medical Journal, vol. 12, pp. 737-738, 2004.

[24] X. Shaohan, D. Bin, C. Yun et al., "Clinical observation of traditional Chinese medicine combined with western medicine on 46 patients with dilated cardiomyopathy," Modern Medical and Health, vol. 18, pp. 2424-2425, 2005.

[25] Y. Yongxuan and Z. Bende, "Clinical observation on the treatment of refractory heart failure of dilated cardiomyopathy with integrated traditional Chinese and western medicine," Integrated Traditional Chinese and Western Medicine Practical Clinical First Aid, vol. 5, pp. 12-13, 1997.

[26] C. Xuebin, W. Chaohong, Z. Yongcheng et al., "Combination of Traditional Chinese Medicine and western medicine in the treatment of dilated cardiomyopathy and heart failure: observation of 21 cases," National Medical Forum, vol. 1, article 36, 1995.

[27] C. Wanqiang, X. Chengxiang, M. Hui et al., "Therapeutic effect of combination of traditional Chinese and western medicine in treatment of dilated cardiomyopathy," Northwest National Defence Medical Journal, vol. 4, pp. 286-287, 1999.

[28] D. Huiwen, G. Duhai, Y. Jie et al., "Clinical study on the effect of Changpu Qidan Decoction on cardiac function in patients with dilated cardiomyopathy," Sichuan Traditional Chinese Medicine, no. 1, pp. 82-84, 2013.

[29] H. Wuyi, "Clinical observation on 23 cases of dilated cardiomyopathy treated with combination of traditional Chinese and western medicine," Chinese Folk Medicine, vol. 7, pp. 69-70, 2012.

[30] H. Qunyan, "Clinical observation on 32 cases of dilated cardiomyopathy treated with combination of traditional Chinese and Western Medicine," Chinese Folk Medicine, no. 9, pp. 9496, 2012.

[31] G. Jinliang, Z. Lihong, and Y. Yuheng, "Combination of traditional Chinese medicine and western medicine in the treatment of dilated cardiomyopathy and heart failure: observation of 30 cases," Tianjin Traditional Chinese Medicine, vol. 4, pp. 291-292, 2011.

[32] Organizing Committee of the Chinese Symposium on Myocardium and Cardiomyopathy, "Summary of the Symposium on myocarditis and cardiomyopathy in China," Journal of Clinical Cardiology, vol. 11, pp. 324-326, 1995.

[33] Member of Editorial Committee of Chinese Journal of cardiovascular diseases, "Summary of the Symposium on myocarditis and cardiomyopathy in China," Chinese Journal of Cardiovascular Diseases, vol. 27, pp. 408-412, 1999.

[34] M. Wenzhu and Z. Jinan, Myocardial Disease, Jiangsu Science and Technology Press, Nanjing, China, 2001.

[35] Y. Rengao and L. Zaiying, Internal Medicine, vol. 159, People's Medical Publishing House, Beijing, China, 6th edition, 2004.

[36] L. Zaiying and Z. Nanshan, Internal Medicine, People's Medical Publishing House, Beijing, China, 7th edition, 2012.

[37] C. Haozhu, Practical Department of Internal Medicine, vol. 9th, People's Medical Publishing House, Beijing, China, 1993.

[38] Editorial Board of Practical Department of Internal Medicine. Shanghai Medical University, Practical Department of Internal Medicine, People's Medical Publishing House, Beijing, China, 8th edition, 1986.

[39] J. P. T. Higgins and S. Green, Cochrane Handbook for Systematic Reviews of Interventions, Version 5.1.0, The Cochrane Collaboration, Oxford, UK, 2011, http://handbook.cochrane.org/.

[40] M. Borenstein, L. V. Hedges, J. P. T. Higgins, and H. R. Rothstein, "Part 3: fixed-effect versus random-effects models," in Introduction to Meta-Analysis, pp. 61-102, John Wiley \& Sons, West Sussex, UK, 2009.

[41] C. S. Rihal, R. A. Nishimura, L. K. Hatle, K. R. Bailey, and A. J. Tajik, "Systolic and diastolic dysfunction in patients with clinical diagnosis of dilated cardiomyopathy: relation to symptoms and prognosis," Circulation, vol. 90, no. 6, pp. $2772-$ 2779, 1994.

[42] S. Yanwen and Z. Jinzhi, "Effect of Astragalus on viral heart disease," Journal of Clinical Cardiovascular Diseases, vol. 16, no. 7, pp. 330-331, 2000.

[43] G. H. Gyatt, M. J. Sullivan, P. J. Thompson et al., "The 6-minute walk test: a new measure of exercise capacity in patients with chronic heart failure," Canadian Medical Association Journal, vol. 132, pp. 919-923, 1985.

[44] W. C. Levy, D. Mozaffarian, D. T. Linker et al., "The Seattle Heart Failure Model: prediction of survival in heart failure," Circulation, vol. 113, no. 11, pp. 1424-1433, 2006.

[45] X. Yang, "Effect of Compound Danshen Injection on plasma CGRP and ET levels in patients with coronary heart disease complicated with congestive heart failure," Chinese Journal of Integrated Traditional Chinese and Western Medicine, vol. 17, no. 2, p. 96, 2001.

[46] H. Ling and C. Keji, "Advances in experimental pharmacology of Astragalus on cardiovascular system," Chinese Journal of Integrated Traditional Chinese and Western Medicine, vol. 20, no. 3, pp. 234-237, 2000. 
[47] L. Xiaoyan and W. Qinan, "Treatment of 48 cases of senile chronic heart failure with strong heart capsule," Journal of Cardiovascular and Cerebrovascular Diseases, vol. 10, no. 5, pp. 522-523, 2012.

[48] M. Faguang and Z. Yiqin, "Clinical study of Ge Gensu on BNP level in patients with chronic heart failure," Jilin Traditional Chinese Medicine, vol. 26, no. 12, pp. 17-18, 2006.

[49] W. Benxiang, Modern Pharmacology of Traditional Chinese Medicine, Tianjin Science and Technology Press, Tianjin, China, 1997.

[50] S. Yingjun, Pharmacology of Traditional Chinese Medicine, People's Medical Publishing House, Beijing, China, 2000.

[51] F. Hangyu and L. Ganzhong, "Ten years progress in the research of pharmacology of Chinese Materia Medica," Chinese Pharmacological Bulletin, vol. 12, no. 3, pp. 201-206, 1996.

[52] T. Yuansheng and D. Shengming, "Discussion on the treatment of dilated cardiomyopathy," Journal of Traditional Chinese Medicine, vol. 44, no. 10, p. 784, 2003.

[53] G. Ge, Modern Practical Health Statistics, Soochow University Press, Suzhou, China, 2010. 


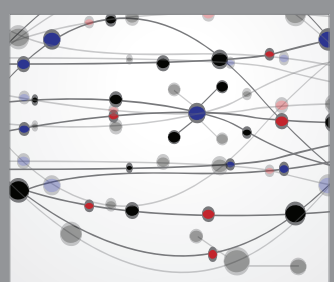

The Scientific World Journal
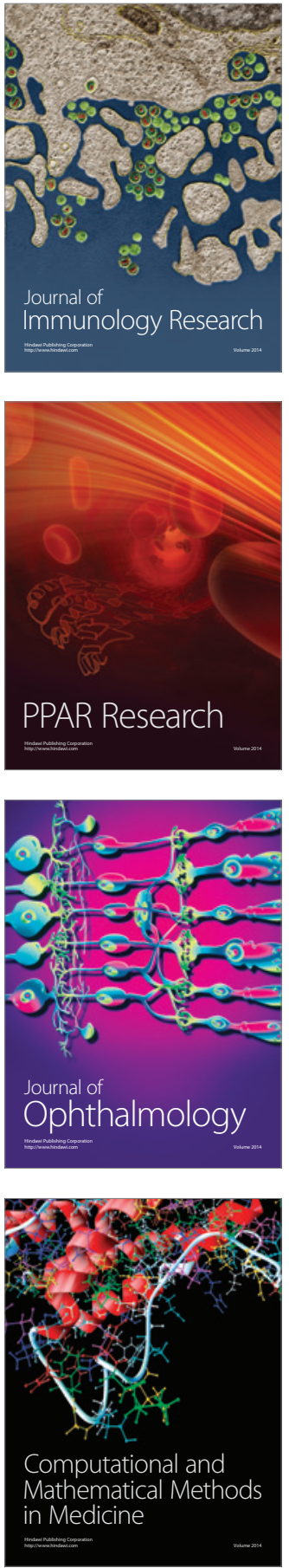

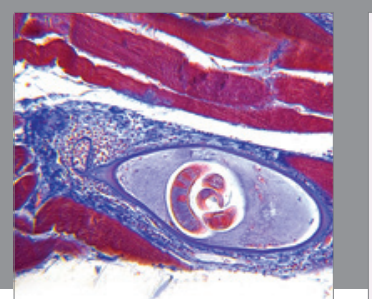

Gastroenterology Research and Practice

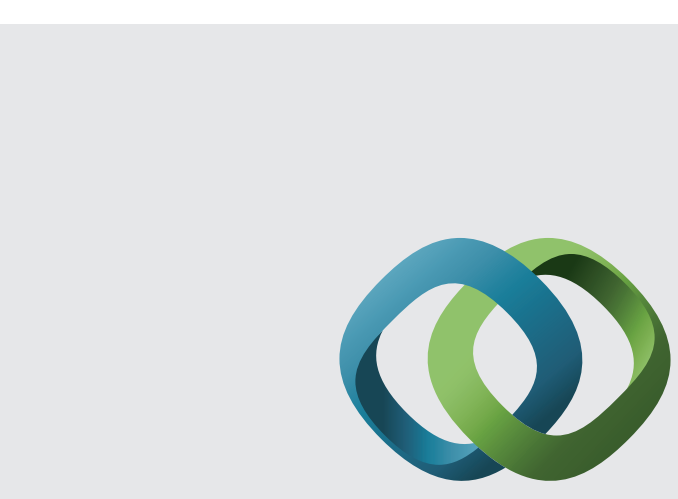

\section{Hindawi}

Submit your manuscripts at

http://www.hindawi.com
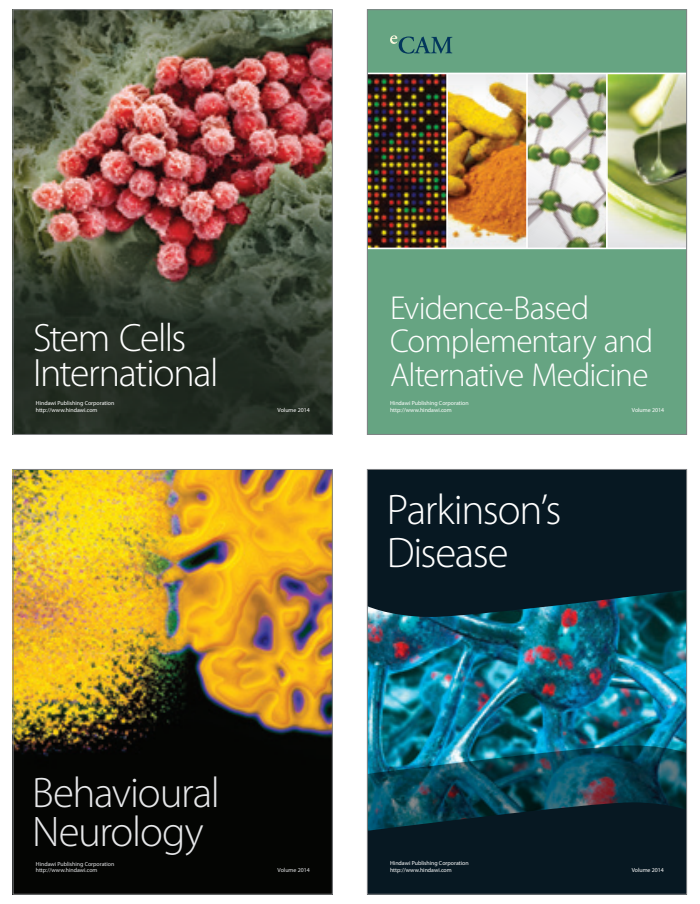
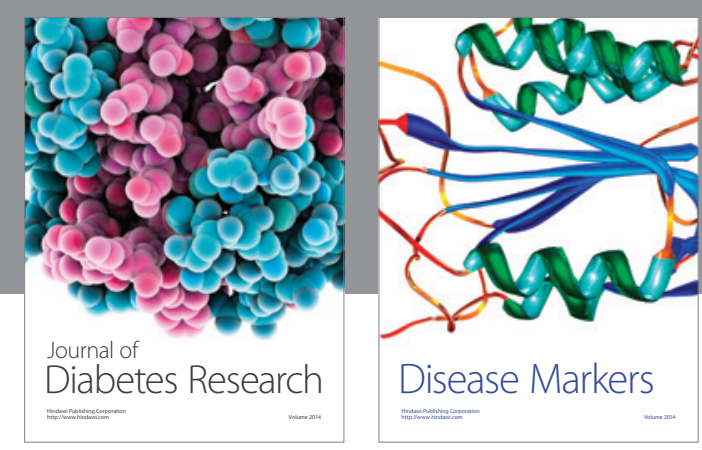

Disease Markers
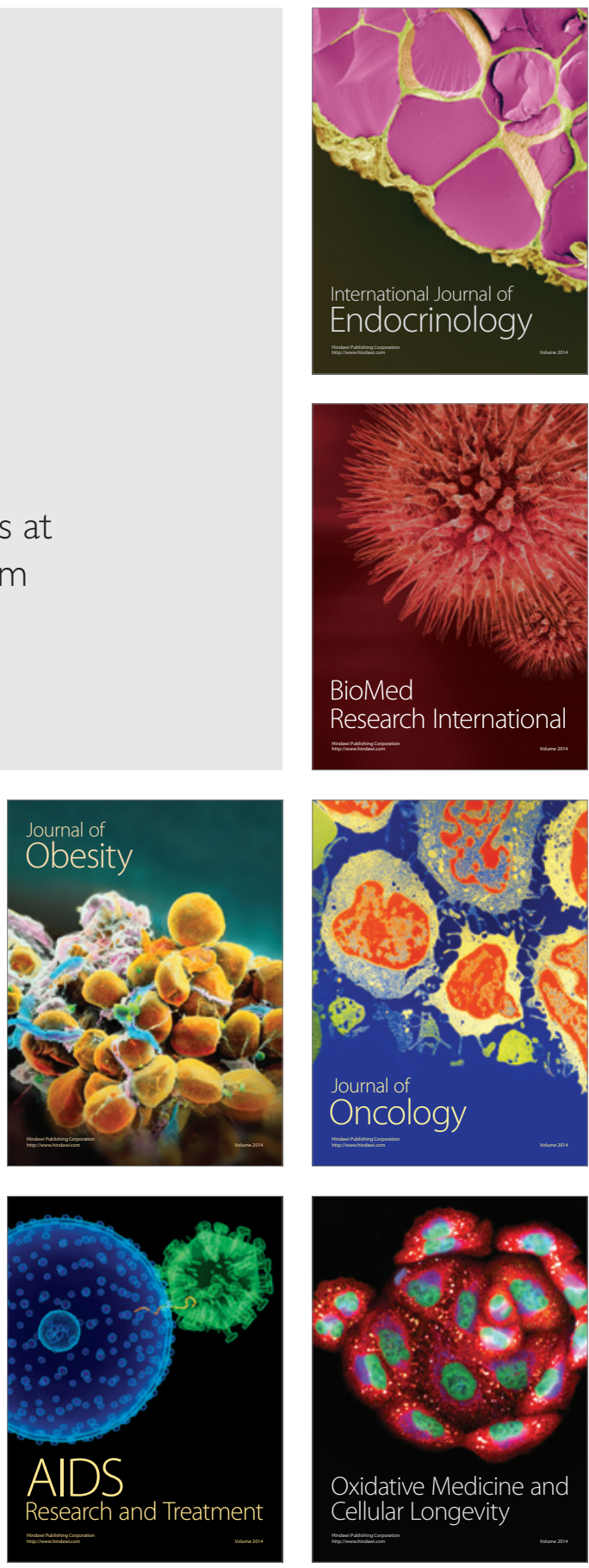